\title{
Forecasting of Runoff and Sediment Yield Using Artificial Neural Networks
}

\author{
Avinash AGARWAL ${ }^{1}$, R. K. RAI ${ }^{2}$, Alka UPADHYAY ${ }^{2}$ \\ ${ }^{1}$ National Institute of Hydrology, Roorkee, Uttarakhand, India \\ ${ }^{2}$ DHI (India) Water \& Environment Pvt. Ltd., New Delhi, India \\ E-mail: rai.raveendra@gmail.com \\ Received June 16, 2009; revised July 16, 2009; accepted July 27, 2009
}

\begin{abstract}
Runoff and sediment yield from an Indian watershed during the monsoon period were forecasted for different time periods (daily and weekly) using the back propagation artificial neural network (BPANN) modeling technique. The results were compared with those of single- and multi-input linear transfer function models. In BPANN, the maximum value of variable was considered for normalization of input, and a pattern learning algorithm was developed. Input variables in the model were obtained by comparing the response with their respective standard error. The network parsimony was achieved by pruning the network using error sensitivity - weight criterion, and model generalization by cross validation. The performance was evaluated using correlation coefficient (CC), coefficient of efficiency (CE), and root mean square error (RMSE). The single input linear transfer function (SI-LTF) runoff and sediment yield forecasting models were more efficacious than the multi input linear transfer function (MI-LTF) and ANN models.
\end{abstract}

Keywords: Artificial Neural Network, Forecasting, Runoff, Sediment Yield

\section{Introduction}

Rainfall-runoff-sediment yield is the most complex hydrological phenomenon to comprehend due to tremendous spatial variability of watershed characteristics and precipitation patterns, making the physical modeling quite complex and involved. The quantity of runoff and sediment yield resulting from a given rainfall depends mainly on rainfall intensity, duration, and distribution besides others, such as initial soil moisture, land use, slope, etc. The runoff is critical to many water resources activities, for example, design of flood protection works, protection of agricultural lands, planning of water storage and release, etc. The erosion in the watershed may be occurred due to rainfall and runoff, and degrades its land. The sediment transport caused the reduction of storage capacity of rivers and reservoirs. Also, sediments can carry pollutants such as radioactive materials, pesticides and nutrients, and their transportation is generally avoided.

A number of linear and non-linear hydrological models have been developed since 1930's for describing the processes of rainfall-runoff, runoff-sediment yield, and rainfall-runoff-sediment yield in a watershed fluvial system, and these are also useful in forecasting. These mod- els can be broadly classified as lumped, conceptual, hydrological, and hydraulic models. The physically based classical models requires wide range of parameters related to land uses, soil characteristics, soil horizon, watershed treatment, man made activities, conservation practices, soil moisture variation, topographic data, surface roughness, etc. These parameters vary significantly over a space and time, and very difficult to monitor. Under these circumstances, classical models require assumption of the parameters. Most common assumption to be made for describing the rainfall-runoff-sediment yield process is: sediment produced in the catchments is uniformly distributed over the catchments, uniform soil group, approximation of slopes, etc. These assumptions create lumped-ness in the physically based distributed classical model. On the other hand, ANN based approach yields satisfactory results without going into the details of catchments characteristics. The artificial neural network (ANN) approach comprises both linear and nonlinear concepts in model building, and can be operated with the dynamic or memory less input-output system. It has the following major advantages [1]. 1) An ANN model does not require a prior knowledge of the system and, therefore, can be applied to solve the problems not clearly defined, 2) The model has more tolerance to noise and incomplete data, and thus, requires less data 
for model development, and 3) The results are the outcome of the collective behavior of data, and thereby, the effect of outlier is minimized. In ANN, the gradient descent search optimization embedded with back propagation algorithm [2] is quite popular in ANN for exploring diverse areas such as bio-medical, engineering, image processing, water resources, and others $[3,4]$.

The hydrologic applications of ANN include modeling of daily rainfall-runoff-sediment yield process, snowrainfall process; assessment of stream ecological and hydrological responses to climate change; rainfall-runoff forecasting, sediment transport and groundwater quality forecasting, and groundwater remediation. A good overview of ANN application to rainfall-runoff simulation and forecasting is available elsewhere [5-16]. Imrie improved the generalization by adding a guidance system to the cascade correlation learning architecture and extrapolation properties using an activation function. Wilby interpreted the internal behavior of an ANN-based rainfall-runoff model by deleting all the nodes other than the hidden nodes and comparing the state variables and internal fluxes. Danh and Elshorbagy proposed back propagation artificial neural network (BPANN) models for runoff forecasting using fixed stopping criterion and independent variables, respectively, and compared them for performance with the available conceptual models.

It is apparent from above that the generalization of ANN models for varying data sets and their application to sediment modeling do not appear to have been studied extensively or even attempted. Thus, the objective of the study is to develop memory-based linear transfer function, ANN-based runoff and sediment yield forecasting models for daily and weekly time periods; and to evaluate the model performance for their forecasting abilities using the data of the Vamsadhara River watershed of India.

\section{Model Development}

The linear transfer function (LTF) models require minimum input and computation, and yield the results of desired accuracy [17]. In an LTF, two or more time-dependent observations are linked as:

$$
S_{t}=\sum_{j=1}^{p} a_{j} S_{t-j}+\sum_{j=1}^{q} b_{j} R_{t-j+1}+\sum_{j=1}^{r} c_{j} Q_{t-j+1} \cdots \cdots
$$

where, $\mathrm{S}_{\mathrm{t}}$ is the dependent observation; $\mathrm{R}_{\mathrm{t}}$ and $\mathrm{Q}_{\mathrm{t}}$ are independent observations; $\mathrm{p}, \mathrm{q}, \mathrm{r}$ are the response or time memory; and $\mathrm{a}_{\mathrm{j}}, \mathrm{b}_{\mathrm{j}}, \mathrm{c}_{\mathrm{j}}$ are the parameters associated with the $\mathrm{j}^{\text {th }}$ variable. Least square method can be used to solve the set of $t$ linear equations for parameters. Representing $\left[a_{1}, a_{2}, \ldots, a_{p}, b_{1}, b_{2}, \ldots, b_{q}, c_{1}, c_{2}, \ldots, c_{r}\right]^{T}$ as $\hat{H}$, the variance of the response $\{\operatorname{var}(\hat{\mathrm{H}})\}$ is given as [17]: $\operatorname{Var}(\hat{\mathrm{H}})$ $=\left[\mathrm{A}^{\mathrm{T}} \mathrm{A}\right]^{-1} \sigma^{2}$, where $\mathrm{A}$ is the input matrix and $\sigma^{2}$ is the variance of error term $\left(e_{t}\right)$ expressed as:

$$
\sigma^{2}=(t-p-q-r)^{-1} \sum_{j=1}^{t} e_{j}^{2}
$$

The $\operatorname{Var}(\hat{\mathrm{H}})$ helps in parsimonious selection of response or time memory by comparing the respective standard error (SE) associated with each response ( $\hat{H} \geq \sqrt{\operatorname{Var}(\hat{H})})$ as follows. The initially selected response value is increased one by one and if the resulting $\hat{\mathrm{H}}$ is less than the respective standard error $\{\sqrt{\operatorname{Var}(\hat{\mathrm{H}})}\}$, otherwise the response value is decreased one by one. The obtained response value represents the number of successive past events of the variable affecting output [17].

In a feed forward BPANN scheme, nodes of the input layer receive the normalized data set (input). The weighted sum corresponding to each node of next layer is calculated and passed to next layer usually through a sigmoid activation function. For updating the weights of interconnection, the error (E) is calculated at the output as;

$$
E=\frac{1}{2} \sum_{1}^{k}\left[d_{(k)}-O_{(k)}\right]^{2}
$$

This error is propagated back to hidden layer and finally to input layer. Here, $\mathrm{d}_{(\mathrm{k})}$ is the observed output at the $\mathrm{k}^{\text {th }}$ node of the output layer and $\mathrm{O}_{(\mathrm{k})}$ is the estimated output at the $\mathrm{k}^{\text {th }}$ node of the output layer. In all iterations, weights are updated using $\mathrm{W}_{(\mathrm{ij}) \mathrm{n}+1}=\mathrm{W}_{(\mathrm{ij}) \mathrm{n}}+\Delta \mathrm{W}_{(\mathrm{ij}) \mathrm{n}}$.

The speed of convergence in gradient descent is normally increased by introducing a momentum term $\beta(0<$ $\beta<1$ ) considering the effect of previous weight change as:

$$
W_{(i j) n+1}=W_{(i j) n}+\Delta W_{(i j) n}+\beta\left[W_{(i j) n}-W_{(i j) n-1}\right]
$$

The change in weights $(\Delta \mathrm{W})$ in the direction of negative gradient is given by $\Delta \mathrm{W}_{(\mathrm{ij})}=-\alpha \quad \partial \mathrm{E} / \partial \mathrm{W}_{(\mathrm{ij})}$, where $\alpha$ is learning rate such that $0<\alpha<1$. The learning rate governs the rate of change of weights.

The network parsimony (minimum network structure) can be achieved through $\mathrm{A}$ information criterion (AIC) [18], B information criterion (BIC) [19], or by pruning of network [20]. AIC and BIC utilize SE statistic for deciding the number of free parameters [21]. In pruning, [20] suggested the use of error sensitivity $\mathrm{Se}_{(\mathrm{ij})}$ with respect to weight $\mathrm{W}_{(\mathrm{ij})}$ for elimination of the respective weight without involvement of excessive calculations. $\mathrm{Se}_{(\mathrm{ij})}$ is defined as:

$$
S e_{(i j)}=-\frac{\partial \mathrm{E}}{\partial \mathrm{W}_{(\mathrm{ij})}} \int_{\mathrm{W}_{(\mathrm{ij})}^{\mathrm{f}}}^{\mathrm{W}_{(\mathrm{ij})}^{\mathrm{i}}=0} \mathrm{~W}_{(\mathrm{ij})}^{\mathrm{f}}
$$

Finally, $\mathrm{Se}_{(\mathrm{ij})}$ with respect to $\mathrm{W}_{(\mathrm{ij})}$ reduces to:

$$
S e_{(i j)}=\sum_{1}^{\mathrm{it}} \frac{\Delta \mathrm{W}_{(\mathrm{ij})}{ }^{2}}{\alpha} \cdot \frac{\mathrm{W}_{(\mathrm{ij})}^{\mathrm{f}}}{\mathrm{W}_{(\mathrm{ij})}^{\mathrm{f}}-\mathrm{W}_{(\mathrm{ij})}^{i}} .
$$


Table 1. Summary of annual hydrological data of Vamsadhara River basin.

\begin{tabular}{ccccccc}
\hline Year & $\begin{array}{c}\text { Weighted Average Rainfall } \\
(\mathrm{mm})\end{array}$ & $\begin{array}{c}\text { Runoff } \\
\left(\mathrm{m}^{3} / \mathrm{s}\right)\end{array}$ & $\begin{array}{c}\text { Runoff } \\
(\mathrm{mm})\end{array}$ & $\begin{array}{c}\text { Sediment yield } \\
(\mathrm{kg} / \mathrm{s})\end{array}$ & $\begin{array}{c}\text { Runoff-Rainfall } \\
\text { Ratio }\end{array}$ & $\begin{array}{c}\text { Sediment Yield-runoff ratio/ } \\
\text { Sediment Concentration } \\
\left(\mathrm{kg} / \mathrm{m}^{3}\right)\end{array}$ \\
\hline 1984 & 965.2 & 13245.2 & 146.3 & 28917.2 & 0.15 & 2.18 \\
1985 & 1079.6 & 17195.9 & 190 & 29802.3 & 0.18 & 1.73 \\
1986 & 971.7 & 20519.6 & 226.7 & 36233 & 0.23 & 1.77 \\
1987 & 715.8 & 6506.6 & 71.9 & 12230.4 & 0.1 & 1.88 \\
1988 & 1053.7 & 25454.9 & 281.2 & 42742.8 & 0.27 & 1.68 \\
1989 & 1074.2 & 19789.9 & 218.7 & 30699.6 & 0.2 & 1.55 \\
1992 & 1028.7 & 40017.2 & 442.1 & 62668.2 & 0.43 & 1.57 \\
1993 & 773.3 & 15005.5 & 165.8 & 20177.2 & 0.21 & 1.34 \\
1994 & 1142.3 & 31896.4 & 352.4 & 33675.8 & 0.31 & 1.06 \\
1995 & 1010.6 & 34237.4 & 378.3 & 30291.5 & 0.37 & 0.88 \\
\hline
\end{tabular}

where, $\mathrm{i}$ and $\mathrm{f}$ indicate the initial and final values of weights. Since the weight update is available during learning, only summation of squares of change in weight, i.e. $\Sigma \Delta \mathrm{W}_{(\mathrm{ij})}{ }^{2}$, is determined for estimation of the sensitivity of error. A comparatively low sensitivity suggests the pruning of the corresponding node.

The model can be generalized by cross-validation, but without ascribing a level of accuracy in the beginning of model formulation. The performance of the developed model is checked in all iterations. In this method, the network is trained on training data set and its statistical performance is evaluated on training and cross-validation data sets. The method monitors the generalized performance, and the process of learning is stopped when there is no more improvement in training along with the performance in cross validation period. For performance, the following statistical and hydrological criteria were used in the present analysis.

\subsection{Correlation Coefficient (CC)}

The correlation between the observed and estimated values is accounted by the correlation coefficient expressed as follows.

$$
C C=\frac{\sum_{\mathrm{j}=1}^{\mathrm{n}}\left\{\left(\mathrm{Y}_{\mathrm{j}}-\overline{\mathrm{Y}}\right)\left(\hat{\mathrm{Y}}_{\mathrm{j}}-\overline{\hat{\mathrm{Y}}}\right)\right\}}{\left\{\sum_{\mathrm{j}=1}^{\mathrm{n}}\left(\mathrm{Y}_{\mathrm{j}}-\overline{\mathrm{Y}}\right)^{2} \sum_{\mathrm{j}=1}^{\mathrm{n}}\left(\hat{\mathrm{Y}}_{\mathrm{j}}-\overline{\hat{\mathrm{Y}}}\right)^{2}\right\}^{1 / 2}} \times 100
$$

where, $\overline{\mathrm{Y}}$ and $\overline{\hat{\mathrm{Y}}}$ are mean of observed and estimated values, $\mathrm{Y}$ and $\hat{\mathrm{Y}}$ are the observed and estimated values respectively and $\mathrm{n}$ is the number of observation.

\subsection{Coefficient of Efficiency (CE)}

Nash and Sutcliffe proposed this non-dimensional criterion on the basis of standardization of the residual variance with initial variance. It is estimated as follows:

$$
C E=\left\{1-\frac{\text { Residual Variance }}{\text { Initial Variance }}\right\} x 100=\left\{1-\frac{\sum_{\mathrm{j}=1}^{\mathrm{n}}\left(\mathrm{Y}_{\mathrm{j}}-\hat{\mathrm{Y}}_{\mathrm{j}}\right)^{2}}{\sum_{\mathrm{j}=1}^{\mathrm{n}}\left(\mathrm{Y}_{\mathrm{j}}-\overline{\mathrm{Y}}\right)^{2}}\right\} x 100 \cdots
$$

A perfect agreement between the observed and estimated values yields the coefficient of efficiency as 100 percent. For zero agreement, all the estimated values must be equal to the observed mean. A negative efficiency shows that the estimated values are less than the observed mean. It can be used to compare the model's relative performance on different watersheds.

\subsection{Root Mean Square Error (RMSE)}

An alternate criterion of residual error is the root mean square error [22] which is expressed as the measure of mean of the residual variance summed over the period, that is:

$$
R M S E=\sqrt{\frac{\text { residual variance }}{\mathrm{n}}}=\left(\frac{\sum_{\mathrm{j}=1}^{\mathrm{n}}\left(\mathrm{Y}_{\mathrm{j}}-\hat{\mathrm{Y}}_{\mathrm{j}}\right)^{2}}{\mathrm{n}}\right)^{1 / 2}
$$

\section{Study Area}

The Vamsadhara river basin is located between $18^{0} 15^{\prime}$ to $19^{0} 55^{\prime}$ north latitudes and $83^{0} 20^{\prime}$ to $84^{0} 20^{\prime}$ east longitudes (Figure 1) situated between Mahanadi and Godavari river basins in South India. The river originates from Kalahandi and travels through a distance of about $254 \mathrm{~km}$ before it joins the Bay of Bengal. Its principal tributaries are Chauldua, Phaphalia, Ganguda, Sanna Nadi, and Mahendrathanaya. The watershed $\left(7820 \mathrm{~km}^{2}\right)$ has six raingauge stations: Kutraguda, Mohana, Gudari, Mohandragarh, Gunur, and Kashinagar. Weighted rainfall for study was estimated by considering the Thiessen po- 


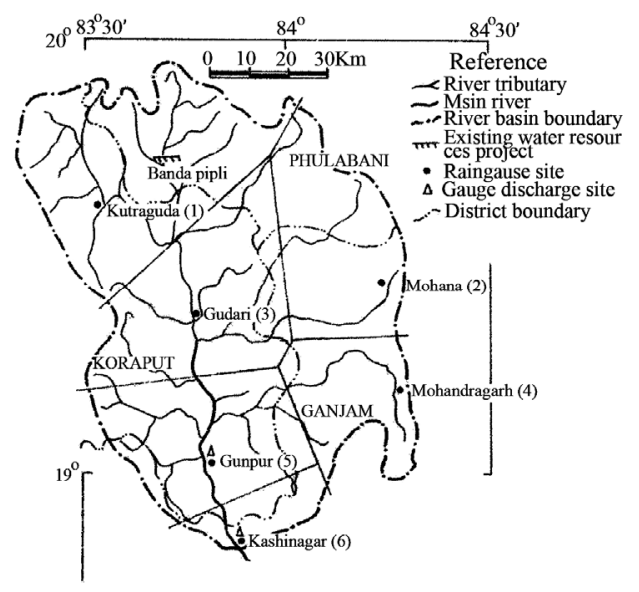

Figure 1. Index map of Vamsadhara River basin showing catchment details.

lygons as shown in Figure 1. The calculated weights for each rainguage, starting from rainfall stations one to six were $0.2640,0.1835,0.2696,0.1096$ and 0.0224 respectively. The yearly weighted rainfall, runoff and sediment yield are shown in Table 1. The mean annual rainfall and temperature varies from 170 to $1280 \mathrm{~mm}$, and 10 to 43 $\mathrm{C}$, respectively and humidity is above $95 \%$ during the monsoon. The soils of area can be classified into mixed red, black soils, red sandy soils, yellow soils, coastal sands, and forest soils, and its surface is mostly covered with Kankar and Murum. The hydro-meteorological data are being collected by India Meterological Department (IMD) and Central Water Commission (CWC), Godavari Mahanadi Circle Division, South Eastern Region, Bhubaneswar, Orissa. The measurements include rainfall, stage and sediment concentration in a one litre of sample. Rainfall is measured by India Meteorological Department (IMD) in the units of $\mathrm{mm} /$ day using a self recording raingauge. The runoff is recorded by $\mathrm{CWC}$ by area velocity method and observed once in a day starting at $8.00 \mathrm{~h}$. The velocities are measured by current metre and using sounding rod. The runoff recorded by CWC is reported in the units of $\mathrm{m}^{3} / \mathrm{s}$. The sediment yield, that is the suspended is measured by taking $1 l$ water sample and is reported in the units of $\mathrm{kg} / \mathrm{m}^{3}$.

In this study, the daily rainfall, runoff, and sediment yield data of monsoon period (June 1-October 31) for 1984-1987 were used for model calibration, and the data of 1988-89 and 1992-95 for cross validation and verification.

\section{Analysis of the Results}

In the present study, the acceptable significance limits only for $\mathrm{CC}$ and $\mathrm{CE}$ for the model were considered as $>$ $75 \%$ and $>60 \%$ respectively. The criterion RMSE is basically used to compare the models and therefore no limits for these criteria have been fixed for evaluating the
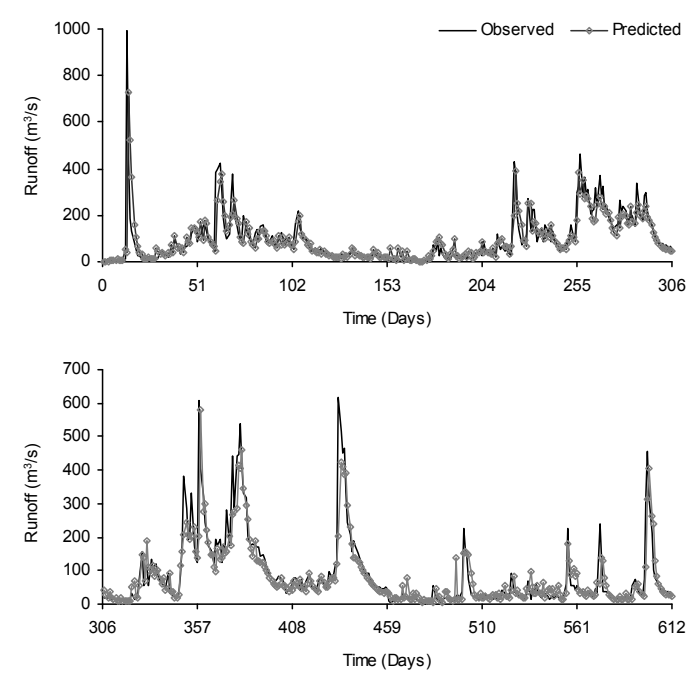

Figure 2. Daily observed and predicted runoff from SI-LTF model during calibration period (1984-87).

performance of a particular model. The descriptive statistic of data used in model development, cross-validation, and verification is shown in Table 1. It is seen that runoff-rainfall ratios for 1992, 1994, and 1995 are higher than those in other years, implying that the verification with former years data may underestimate the runoff. However, sediment concentration values in 1993, 1994, and 1995 are lower than those in the other years, and therefore, the developed models may overestimate the sediment yield in those verification years.

\subsection{Runoff Forecasting}

\subsubsection{Model development}

1) SI-LTF model:

Following the above-described procedure, the single-input linear transfer function (SI-LTF) rainfall (R)runoff $(\mathrm{Q})$ models were developed for daily and weekly time steps, and the results are shown in Table 2. In this table, the value of time memory for input rainfall is a maximum, and for runoff, it is a maximum of three. The time memories of runoff are 3 and 2 respectively for daily and weekly models, indicating that the lumping of time periods from daily to weekly reduced the time memory of the runoff. It can be inferred from the values of $\mathrm{CC}$ and $\mathrm{CE}$ that the daily runoff forecasting model performed better than the weekly model (Table 2). Daily observed and predicted runoff by SI-LTF model during calibration period is shown in Figure 2.

2) MI-LTF model:

The multi-input linear transfer function (MI-LTF) models account for the spatial variation of rainfall over the watershed. Therefore, rainfall values of all raingauge stations, viz., R1 to R6 along with runoff $(\mathrm{Q})$ were utilized in models of the considered time steps, and the results are shown in Table 2 . It is observed that the rainfall 
Table 2. Model order and corresponding parameters for different time periods of runoff forecasting in SI-LTF and MI-LTF models for Vamsadhara River basin.

\begin{tabular}{|c|c|c|c|c|c|c|c|}
\hline \multirow{2}{*}{\multicolumn{2}{|c|}{ Model and variable }} & \multicolumn{3}{|c|}{ Model Parameter Associated with Input time Memory } & \multicolumn{3}{|c|}{ Performance of Developed Model } \\
\hline & & \multirow{2}{*}{$\begin{array}{c}\mathrm{t}-1 \\
3.390\end{array}$} & \multirow{2}{*}{$\begin{array}{c}\mathrm{t}-2 \\
--\end{array}$} & \multirow{2}{*}{$\begin{array}{c}\mathrm{t}-3 \\
--\end{array}$} & \multirow{2}{*}{$\begin{array}{c}\mathrm{CC}(\%) \\
--\end{array}$} & \multirow{2}{*}{$\begin{array}{c}\text { CE (\%) } \\
--\end{array}$} & \multirow{2}{*}{$\begin{array}{c}\text { RMSE } \\
--\end{array}$} \\
\hline SI-LTF & $\mathbf{R}$ & & & & & & \\
\hline (Daily) & $\mathbf{Q}$ & 0.524 & 0.127 & 0.181 & 80.0 & 64.0 & 65.0 \\
\hline \multirow{3}{*}{$\begin{array}{c}\text { SI-LTF } \\
\text { (Weekly) }\end{array}$} & $\mathbf{R}$ & 6.192 & -- & -- & -- & -- & -- \\
\hline & $\mathbf{Q}$ & 0.332 & 0.202 & -- & 62.7 & 37.9 & 490.0 \\
\hline & $\mathbf{R 1}$ & 0.728 & 0.479 & -- & -- & -- & -- \\
\hline \multirow{3}{*}{$\begin{array}{l}\text { MI-LTF } \\
\text { (Daily) }\end{array}$} & R5 & 0.296 & -- & -- & -- & -- & -- \\
\hline & R6 & 2.166 & -- & -- & -- & -- & -- \\
\hline & $\mathbf{Q}$ & 0.448 & 0.249 & -- & 80.0 & 63.3 & 66.0 \\
\hline \multirow{3}{*}{$\begin{array}{l}\text { MI-LTF } \\
\text { (Weekly) }\end{array}$} & R4 & 0.894 & -- & -- & -- & -- & -- \\
\hline & R6 & 5.173 & -- & -- & -- & -- & -- \\
\hline & $\mathbf{Q}$ & 0.333 & 0.203 & -- & 62.9 & 38.1 & 490.0 \\
\hline
\end{tabular}

at Mohana (R2) and Gudari (R3) does not influence the output of any time scale model though these areas are located near the centroid of the watershed. It may be attributed to the presence of a dense forested area in the middle of the watershed acting as a sink. The time memory of the runoff in multi-input daily and weekly is 2 . Again the results infer that the daily runoff forecasting model performed better than weekly model.

3) ANN model:

Artificial neural network (ANN) models developed for daily and weekly bases with sigmoid as activation function by pattern learning were subjected to maximum 5000 iterations. The highest value of respective variable in series was considered for normalization of input and output variables. The learning rate $(\alpha)$ and momentum term $(\beta)$ were assumed constant $(0.5)$ for error convergence. All interconnecting weights were updated using the error of input-output pairs. The pattern learning is governed by the error of each data set, and the interconnecting weights simultaneously adjusted. The processing is however slow as it continuously improved the weights for each data set.

The three-layer network structure was selected so that the number of nodes in the input layer equaled the number of input variables. Due to non-availability of guidelines [1], the number of hidden nodes in the hidden layer(s) was initially taken twice the input nodes [23] and it was increased by one at a time considering the improved generalization and the above pruning criterion. Corresponding to one output, only one node was taken in the output layer. Thus, a three-layer network structure with varying numbers of hidden nodes in the hidden layer was tried, and the performance, in both cross-validation and validation, of the finally selected ANN models for all above mentioned time steps for pattern learning is shown in Table 3 . In this table, the generalized case exhibits least errors in both calibration and crossvalidation. Here, the data of 1984 to 1987 were used in calibration, and the data of 1988 to 1989 and 1992 to 1995 in cross-validation, referred as the first and second verification periods in the text, respectively. Performance of daily models both in calibration and cross-validation is better than the weekly model suggesting that the daily model is better than weekly model.

\subsection{Sediment Yield Forecasting}

\subsubsection{Model Development}

1) SI-LTF model:

These models consisted of rainfall (R), runoff $(\mathrm{Q})$, and sediment yield (Sy), and the results are given in Table 5. Apparently, the results of daily model show the effect of one day preceding sediment yield on today's computed sediment yield. Daily observed and predicted sediment yield by SI-LTF model during calibration period is shown in Figure 5. On the other hand, the weekly model has no preceding sediment yield term(s) in the model, implying that the preceding weekly or higher time step sediment yield have no effect on the current output. The model performance reduces with increased lumping of data to larger time periods. Based on the evaluation criteria, though no model passes the criteria, these could be used cautiously for the study area.

2) MI-LTF model:

Similar to the above, the rainfall values of six rainfall gauging sites were considered in the models developed for various time periods, and the results are given in

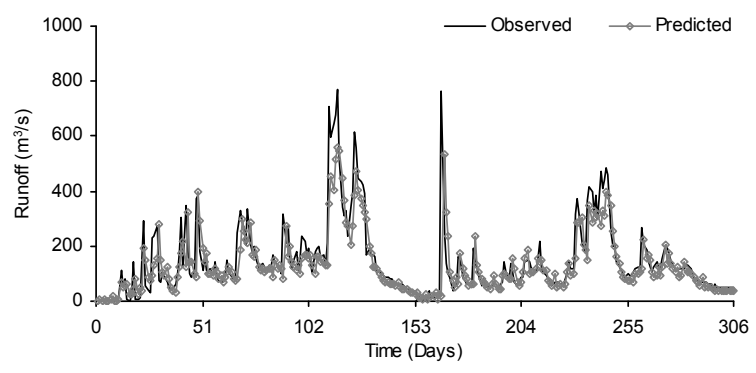

Figure 3. Daily observed and predicted runoff from SI-LTF model during verification period (1988-89). 
Table 3. Pattern learned artificial neural network runoff forecasting models for different time periods for Vamsadhara River basin.

\begin{tabular}{|c|c|c|c|c|c|c|c|c|}
\hline \multirow{3}{*}{ Model } & \multirow{3}{*}{ Structure } & \multirow{3}{*}{ Iteration } & \multicolumn{6}{|c|}{ Performance in model development, \% } \\
\hline & & & \multicolumn{3}{|c|}{ Calibration (1984-1987) } & \multicolumn{3}{|c|}{ Cross validation (1988-1989) } \\
\hline & & & $\mathrm{CC}(\%)$ & $\mathrm{CE}(\%)$ & RMSE & $\mathrm{CC}(\%)$ & $\mathrm{CE}(\%)$ & RMSE \\
\hline Daily & $4,8,1$ & 2490 & 83.8 & 70.1 & 60.0 & 79.5 & 62.5 & 82.0 \\
\hline Weekly & $3,6,1$ & 53 & 65.7 & 43.2 & 470.0 & 68.1 & 37.7 & 600.0 \\
\hline
\end{tabular}

Table 4. Performance evaluation of SI-LTF, MI-LTF and ANN runoff forecasting models during verification stages.

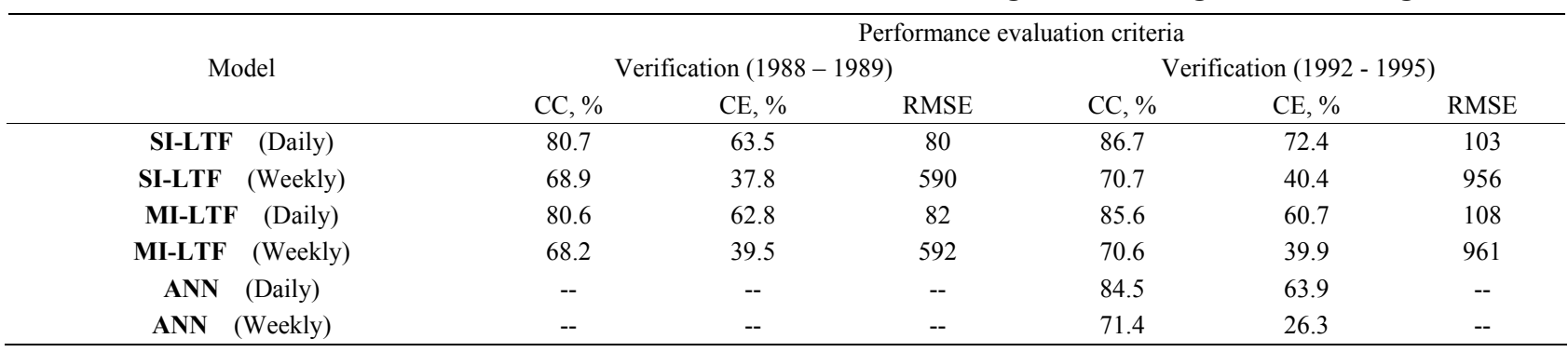

Table 5. Model order and corresponding parameters for different time periods of sediment yield forecasting in SI-LTF and MI-LTF models for Vamsadhara River basin.

\begin{tabular}{|c|c|c|c|c|c|c|c|c|}
\hline \multirow{2}{*}{\multicolumn{2}{|c|}{ Model and variable }} & & \multicolumn{3}{|c|}{ Model parameters associated with input time } & \multicolumn{3}{|c|}{ Performance evaluation of developed model } \\
\hline & & & $\mathrm{t}-1$ & $\mathrm{t}-2$ & $\mathrm{t}-3$ & $\mathrm{CC}, \%$ & $\mathrm{CE}, \%$ & RMSE \\
\hline \multirow{3}{*}{\multicolumn{2}{|c|}{ SI-LTF (Daily) }} & $\mathrm{R}$ & 15.98 & -- & -- & -- & -- & -- \\
\hline & & Q & 0.31 & 0.23 & -- & -- & -- & -- \\
\hline & & Sy & 0.15 & -- & -- & 64.4 & 41.4 & 284.0 \\
\hline \multirow{3}{*}{\multicolumn{2}{|c|}{ SI-LTF (Weekly) }} & $\mathrm{R}$ & 17.60 & 3.21 & -- & -- & -- & -- \\
\hline & & Q & 0.25 & -- & -- & -- & -- & -- \\
\hline & & Sy & -- & -- & -- & 35.0 & 8.7 & 1551.0 \\
\hline \multirow{4}{*}{\multicolumn{2}{|c|}{ MI-LTF (Daily) }} & R5 & 3.54 & -- & -- & -- & -- & -- \\
\hline & & R6 & 13.56 & 0.58 & -- & -- & -- & -- \\
\hline & & Q & 0.61 & -- & -- & -- & -- & -- \\
\hline & & Sy & 0.07 & -- & -- & 65.0 & 42.2 & 282.0 \\
\hline \multirow{4}{*}{\multicolumn{2}{|c|}{ MI-LTF (Weekly) }} & $\mathrm{R} 4$ & 10.73 & 4.79 & -- & -- & -- & -- \\
\hline & & R6 & 4.95 & -- & -- & -- & -- & -- \\
\hline & & Q & 0.17 & -- & -- & -- & -- & -- \\
\hline & & Sy & -- & -- & -- & 40.7 & 13.8 & 1507.0 \\
\hline
\end{tabular}

Table 6. Pattern learned artificial neural network sediment yield forecasting models for different time periods for Vamsadhara River basin.

\begin{tabular}{|c|c|c|c|c|c|c|c|c|}
\hline \multirow{3}{*}{ Model } & \multirow{3}{*}{ Structure } & \multirow{3}{*}{ Iteration } & \multicolumn{6}{|c|}{ Performance in model development } \\
\hline & & & \multicolumn{3}{|c|}{ Calibration (1984-1987) } & \multicolumn{3}{|c|}{ Cross validation (1988-1989) } \\
\hline & & & $\mathrm{CC}$ & $\mathrm{CE}$ & RMSE & $\mathrm{CC}$ & CE $(\%)$ & RMSE \\
\hline Daily & $4,8,1$ & 65 & 63.4 & 40.0 & 290 & 57.3 & 31.0 & 280.0 \\
\hline Weekly & $3,6,1$ & 793 & 46.8 & 21.7 & 1400 & 44.0 & 15.7 & 1300.0 \\
\hline
\end{tabular}

Table 7. Performance evaluation of SI-LTF, MI-LTF and ANN sediment yield forecasting models during verification stages.

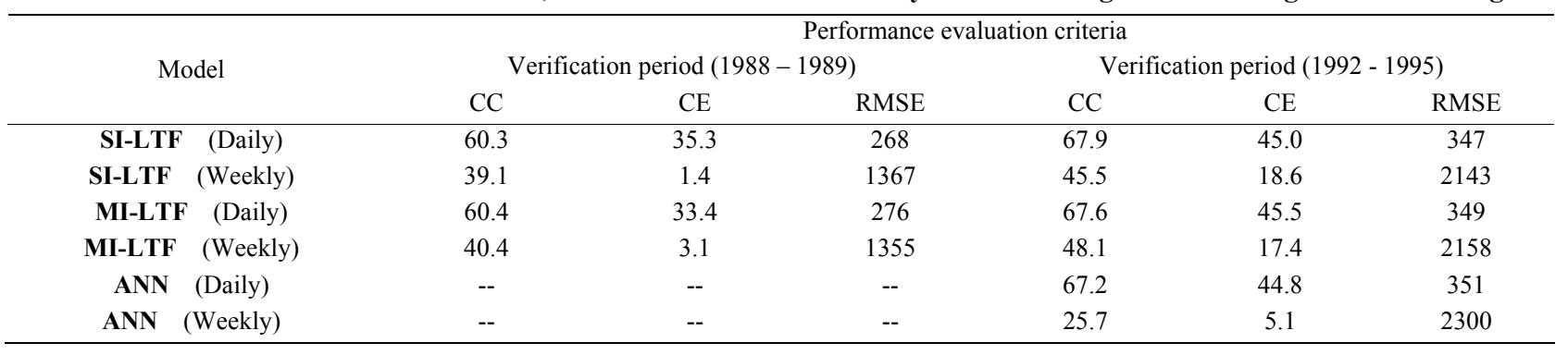


Table 5. Similar to the single-input model, the daily multi-input model indicated the effect of successive past sediment yield on the output whereas weekly did not. In addition, the rainfall of Kutraguda (R1), Mohan (R2) and Gudari (R3) did not influence the output of any of the models despite their being in the center and upper part of the watershed, perhaps due to the presence of forest and better soil conservation practices in the Koraput district, which covers the polygon area of Kutraguda, Mohan and Gudari rain gauge sites (Figure 1). As seen and inferred from Table 5, the lumping of time periods improved the model performance in calibration.

3) ANN model:

Similar to above, the ANN models for various time
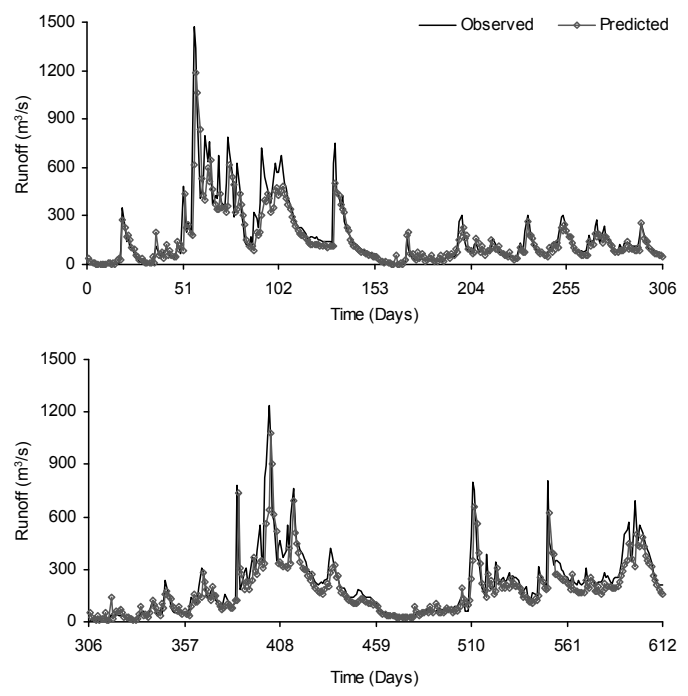

Figure 4. Daily observed and predicted runoff from SI-LTF model during verification period (1992-95).
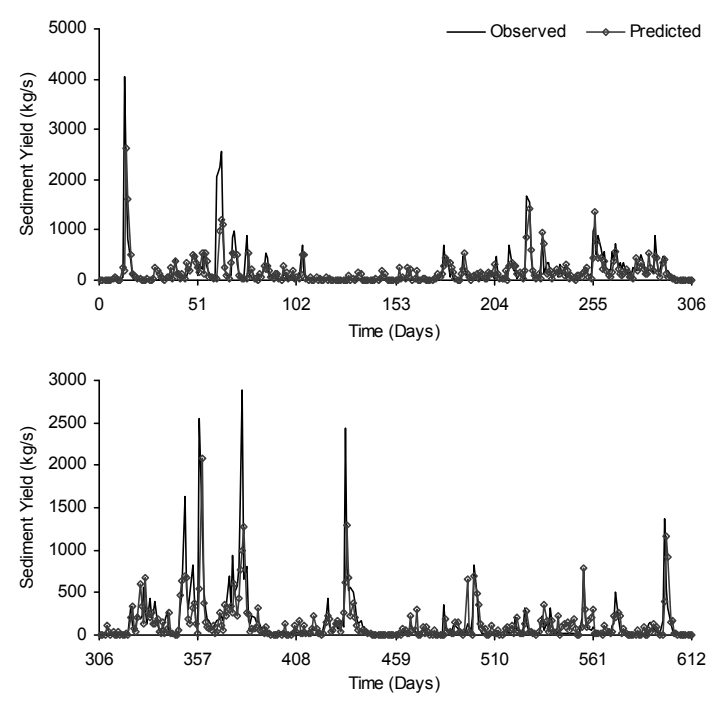

Figure 5. Daily observed and predicted sediment yield from SI-LTF model during calibration period (1984-87).

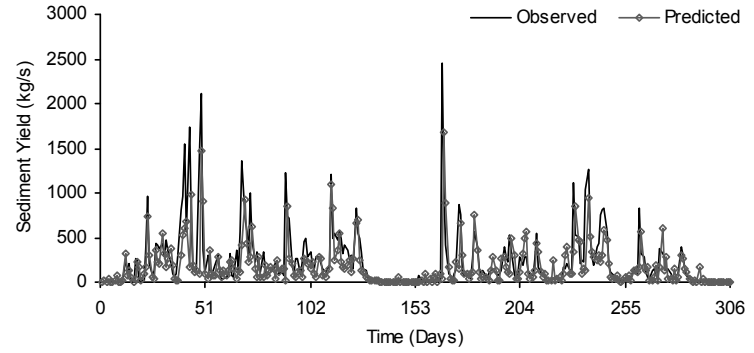

Figure 6. Daily observed and predicted sediment yield from SI-LTF model during verification period (1988-89).
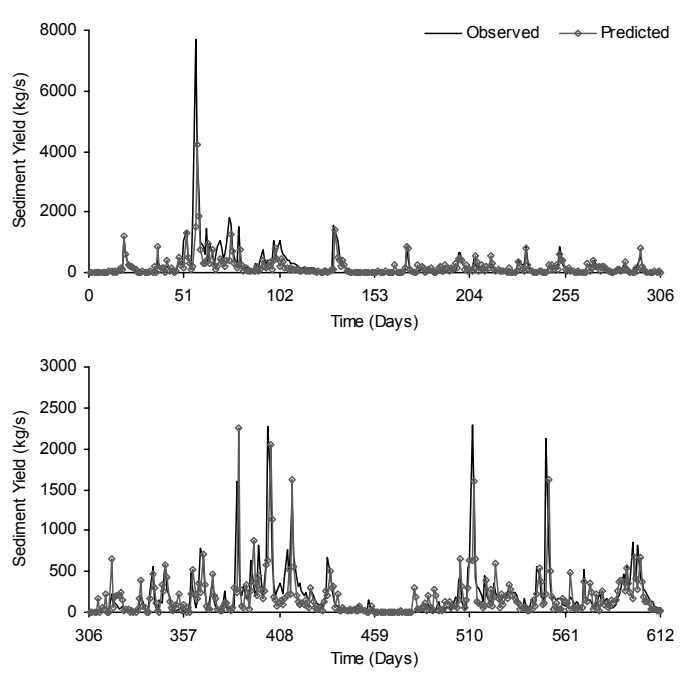

Figure 7. Daily observed and predicted sediment yield from SI-LTF model during verification period (1992-95).

steps were developed for sediment yield. The models were calibrated on 1984 to 1987 data set, cross-validated for maximum generalization with the data of first verification period (1988-1989). The ANN structure was selected as explained earlier, and the number of hidden nodes were selected on the bases of improved generalization and pruning criteria. The values of $\mathrm{CC}$ and $\mathrm{CE}$ indicated no model to perform well.

\subsubsection{Model Verification}

Similar to the models performance in calibration, Table 7 shows non-workability of all the models in verification probably due to high variation of sediment concentration (Table 1) and nonhomogeneous data. However, the daily model worked better than the weekly model. Daily observed and predicted sediment yield by SI-LTF model during both the verification periods is shown in Figure 6 and 7.

\section{Conclusions}

The following conclusions can be drawn from the study:

1) A three-layered ANN structure with the number of 
nodes in hidden layer as twice of the input nodes was the best generalized model obtained in less than 5000 iterations.

2) The daily SI-LTF, MI-LTF, ANN models worked well in runoff forecasting, whereas others failed in calibration as well as in both the verification periods. The daily SI-LTF model was superior to daily MI-LTF model in calibration as well as in both the verification periods. However, the daily ANN model showed an improvement over the former in calibration, but was slightly poor in cross-validation as well as in verification.

3) Any of the proposed SI-LTF, MI-LTF, ANN models can be useful for sediment yield forecasting with little variation in accuracy.

\section{References}

[1] A. S. Tokar and M. Markus, "Precipitation-runoff modelling using artificial neural networks and conceptual models," Journal of Hydrologic Engineering, Vol. 5, No. 2, pp. 156-161, 2000.

[2] D. E. Rumelhart, G. E. Hinton, and R. J. Williams, "Learning internal representations by error propagation," Parallel Distributed Processing, MIT Press, Cambridge, Vol. I, pp. 318-362, 1986.

[3] D. E. Rumelhart, B. Widrow, and M. A. Letr, "The basic ideas in neural networks" Communications of the ACM, Vol. 37, No. 3, pp. 87-92, 1994.

[4] A. Y. Shamseldin, K. M. O'Connor, and G. C. Liang, "Methods for combining the outputs of different rainfall-runoff models," Journal of Hydrology, Vol. 197, pp. 203-229, 1997.

[5] "ASCE (2000a) Task Committee on application of artificial neural networks in hydrology," Artificial Neural Networks in Hydrology, I: Preliminary Concepts, Journal of Hydrologic Engineering, ASCE, Vol. 5, No. 2, pp. 124-137.

[6] "ASCE (2000b) Task Committee on application of artificial neural networks in hydrology" Artificial Neural Networks in Hydrology, II: Hydrologic Application, Journal of Hydrologic Engineering, ASCE, Vol. 5, No. 2, pp. 115-123.

[7] A. Jagadeesh, B. Zhang, and R. S. Govindaraju, "Comparison of ANNs and empirical approaches for predicting watershed runoff," Journal of Water Resources Planning and Management, Vol. 126, No. 3, pp. 156-166, 2000.

[8] A. S. Tokar and M. Markus, "Precipitation-runoff modelling using artificial neural networks and conceptual models," Journal of Hydrologic Engineering, Vol. 5, No. 2, pp. 156-161, 2000.

[9] H. M. Nagy, K. Watanabe, and M. Hirano, "Prediction of sediment load concentration in rivers using artificial neural network model,” J. Hydraulic Engrg., Vol. 128, No.
6, pp. 588-595, 2002.

[10] M. P. Rajurkar, U. C. Kothyari, and U. C. Chaube, "Modeling of the daily rainfall-runoff relationship with artificial neural networks," Journal of Hydrology, Vol. 285, pp. 96-113, 2004.

[11] K. P. Sudheer and S. K. Jain, "Radial basis function neural network for modeling rating curves." J. Hydrologic Engrg., Vol. 8, No. 3, pp. 161-164, 2003.

[12] T. W. Kim and J. B. Valdes, "Nonlinear model for drought forecasting based on a conjunction of wavelet transforms and neural networks," J. Hydrologic Engrg., Vol. 8, No. 6, pp. 319-328, 2003.

[13] H. Moradkhani, K. L. Hsu, H. V. Gupta, and S. Sorooshian, "Improved streamflow forecasting using selforganizing radial basis function artificial neural networks," Journal of Hydrology, Vol. 295, pp. 246-262, 2004.

[14] J. Olsson, C. B. Uvo, K. Jinno, A. Kawamura, K. Nishiyama, N. Koreeda, T. Nakashima, and O. Morita, "Neural networks for rainfall forecasting by atmospheric downscaling." J. Hydrologic Engrg., Vol. 9, No. 1, pp. 1-12, 2004.

[15] Keskin, M. Erol, and T. Özlem, “Artificial neural network models of daily pan evaporation" Journal of Hydrologic Engrg., Vol. 11, No. 1, pp. 65-70. 2006

[16] N. S. Raghuwanshi, R. Singh, and L. S. Reddy, "Runoff and sediment yield modeling using artificial neural networks: Upper siwane river," J. Hydrologic Engrg., India, Vol. 11, No. 1, pp. 71-79, 2006.

[17] J. Johnston, Econometric Methods, McGraw Hill, Tokyo, 1972.

[18] H. Akaike, "A new look at the statistical model identification," IEEE Transactions on Automatic Control, Vol. AC-19, pp. 716-723, 1974.

[19] Rissanenj, "Modeling by short data description," Automation, Vol. 14, pp. 465-471, 1978.

[20] E. D. Karnin, "A simple procedure for pruning back propagation trained neural networks," Institute of Electrical and Electronics Engineers Transactions on Neural Networks, Vol. 1, No. 20, pp. 239-242, 1990.

[21] Z. X. Xu and J. Y. Lijy, "Short term inflow forecasting using an artificial neural network model," Hydrological Process, Vol. 16, pp. 2423-2439, 2002.

[22] P. S. Yu, C. L. Liu, and T. Y. Lee, "Application of a transfer function model to a storage runoff process," Stochastic and Statistical Methods in Hydrology and Environmental Engineering, Vol. 3, pp. 87-97, 1994.

[23] K. W. Hipel, A. Ian, U. S. Panum, and V. P. Singh, "Stochastic and statistical methods in hydrology and environmental engineering," The series analysis in hydrology and environmental engineering, Kluwer Academic Publishers, The Netherlands, Vol. 3, 1994. 